\title{
NUMERICAL SIMULATION AND EXPERIMENTAL TESTING OF TOPOLOGICALLY OPTIMIZED PLA CERVICAL IMPLANTS MADE BY ADDITIVE MANUFACTURING METHODICS
}

\author{
Jozef ŽIVČÁK*, Radovan HUDÁK*, Marek SCHNITZER*, Tomáš KULA** \\ ${ }^{*}$ Faculty of Mechanical Engineering, Department of Biomedical Engineering, \\ Technical University of Košice, Letná 9, 04200, Košice, Slovakia \\ ${ }^{*}$ Faculty of Mechanical Engineering, Department of Applied Mechanics and Mechanical Engineering, \\ Technical University of Košice, Letná 9, 04200, Košice, Slovakia \\ jozef.zivcak@tuke.sk, radovan.hudak@tuke.sk, marek.schnitzer@tuke.sk, tomas.kula@tuke.sk \\ received 31 July 2017, revised 13 June 2018, accepted 15 June 2018
}

\begin{abstract}
The article focuses on compressive axial loading experimental testing and simulations of topologically optimized design and additively manufactured cervical implants. The proposed platform design is based on anatomical and biomechanical requirements for application in the cervical area. Thanks to new ways of production, such as additive manufacturing, and new software possibilities in the field of structural analysis, which use the finite element method and analysis, it is possible to execute topological optimization of an implant in construction solution, which would be impossible to make by conventional methods. The contribution of this work lies in investigation of 3D printed PLA cervical implant usage in surgical intervention and creation of a numerical static loading modelling methodics and subsequent experimental confirmation of the modelling correctness.
\end{abstract}

Keywords: Topological Optimization, Cervical Implant, Additive Manufacturing, FEA, Numerical Simulation, PLA

\section{INTRODUCTION}

The proposed platform design of the cervical implant is based on the anatomical and biomechanical parameters of the cervical spine which are currently being used in surgical procedure spinal fusion, aiming to replace the damaged intervertebral disc or for fusion of the individual segments of the vertebra. The spinal interbody fusion cage could be solid, porous, hollow implant, either cylindrical or nearly cuboid in shape and it can. It can replace the degenerative disc and distract the intervertebral body, thus restoring physiological disc height. The bone grafts can be inserted into the hollow and porous cage allowing the growth of bone through the cage, resulting inner body fusion. Furthermore, it can increase the mechanical strength and fusion rate (Kani and Chew, 2018; Mende et al., 2018). These implants are currently created with conventional manufacturing technologies, e.g. milling, in cases of metal implants or by plastic injection (Yin et al., 2017; Zivcak and Hudak, 2001). These implants are usually created as monoliths without the possibility to manufacture internal structures which creates the opportunity for topological optimization based on numerical analysis and subsequent implementation for production with the use of additive manufacturing technology which makes the manufacturing of internal structures possible.

Within the scope of the topologically optimized design Zhong et al. (2006) investigated topological optimization of lumbar intervertebral cages, this study attempts to prevent the stress shielding effect (the implants is substantially more dense than its surroundings for its application) which is in spinal fusion displayed as the subsidence of the implant based on experimentally calculated parameters in the cervical spine area. Subsidence is a complication whereby the patient's disc height decreases, causing discomfort (Eck et al., 2000; Gzik et al., 2008; Teng et al., 2017).

This paper investigates mechanical properties of topologically optimized design of the intervertebral cage regarding to surgical intervention usage and in addition, the study compares experimentally measured values of additively produced PLA intervertebral cage with numerically calculated values based on material library data.

Aim of the optimization was to find out if optimized design prepared for auotologous bone graft injection withstand compressive axial loading as human vertebra in cervical spine.

The topologically optimized design is built on finite element method (FEM) calculation and finite element analysis (FEA) executed in NX NASTRAN software and experimental tested data executed on tensile testing equipment TIRA TEST2300.

\section{MATERIALS AND METHODS}

A total of four numerical simulations and one experimental testing of intervertebral cage platform design were constructed and tested in this study.

\subsection{Part design and preparation of the finite element model}

Intervertebral cage design and construction solution was created to fulfill strict anatomical and biomechanical parameters of the cervical spine based on relevant studies and articles (Gzik et al., 2008; Steffen et al., 2000; Wang, 1996). Parameter of the implant varies from the placement. Our test cage is designed for the intervertebral space $\mathrm{C} 2 / \mathrm{C} 3$.

Basic dimensions of test cage: length $-12.5 \mathrm{~mm}$, width $1.2 \mathrm{~mm}$, height $-7 \mathrm{~mm}$. The model was created in software SIEMENS NX 10. A part of SIEMENS NX 10 software is FEM software NASTRAN with wall thickness analysis feature which is very helpful for topological optimization and comparison of optimized construction solutions, because it shows localities with maximal wall thickness which is relevant optimization criterion. 

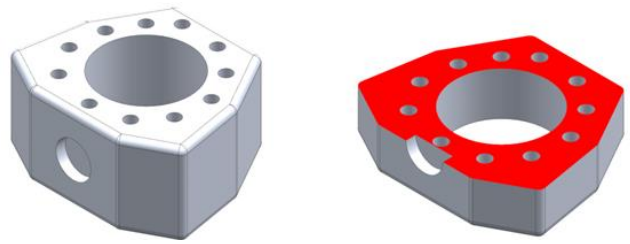

Fig. 1. Intervertebral cage platform design with cross section

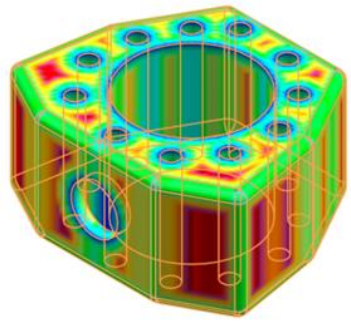

Fig. 2. Wall thickness analysis

Wall thickness analysis shows red colored area (Fig.2) which represents the largest thickness of the wall respectively area with the largest volume of the material (Ivanco et al., 1994). For the accurate results of FEM simulation the input data must correspond with the real environment. In this study PLA - poly-lactidacid was chosen as a construction material, because nowadays it is trend to use biodegradable materials in surgical interventions (Chen et al., 2013; Kandziora et al., 2001). Mechanical properties are shown in Tab. 1.

Tab. 1. Mechanical properties of PLA vs. Cortical bone (Gillet, 2008; Pintar et al., 1998; NX NASTRAN, 2017)

\begin{tabular}{|c|c|c|c|c|}
\hline Propert. & $\begin{array}{c}E[\mathrm{GPa}] \\
\text { Young's } \\
\text { Modulus }\end{array}$ & $\begin{array}{c}\mu[-] \\
\text { Poisson's } \\
\text { Ratio }\end{array}$ & $\begin{array}{c}R_{e}[\mathrm{MPa}] \\
\text { Yield } \\
\text { Strength }\end{array}$ & $\begin{array}{c}R_{m}[\mathrm{MPa}] \\
\text { Ultimate } \\
\text { Tensile } \\
\text { Strength }\end{array}$ \\
\hline PLA & 5.6 & 0.36 & varies & varies \\
\hline $\begin{array}{c}\text { Cortical } \\
\text { bone }\end{array}$ & 12 & 0.6 & $\begin{array}{c}125 \\
\text { longitud. }\end{array}$ & $\begin{array}{c}130 \\
\text { longitud. }\end{array}$ \\
\hline
\end{tabular}

\subsection{Numerical simulation base and algorithm}

In this case study testing in linear and also in nonlinear area is needed.

For linear area (LFEA) is important a system solution of linear algebraic equations:

$K(D)=R$

For nonlinear (NFEA) area is important a system solution of nonlinear algebraic equations:

$K(D) D=R(D)$

where: $\mathrm{K}$ - is the stiffness matrix, $\mathrm{D}$ - is a vector containing displacements in nodes, $\mathrm{R}$ - is a vector containing external forces (Bocko and Segl'a, 2016; Matishen, 2012; Seweryn and Molski, 1996). For numerical study of implant behavior under the influence of load was also used NASTRAN software. Algorithm of the simulation has four steps: 1. CAD model creation, 2. FE model creation, 3. Boundary conditions definition, 4. Numerical and graphical results analysis (Fig.3).
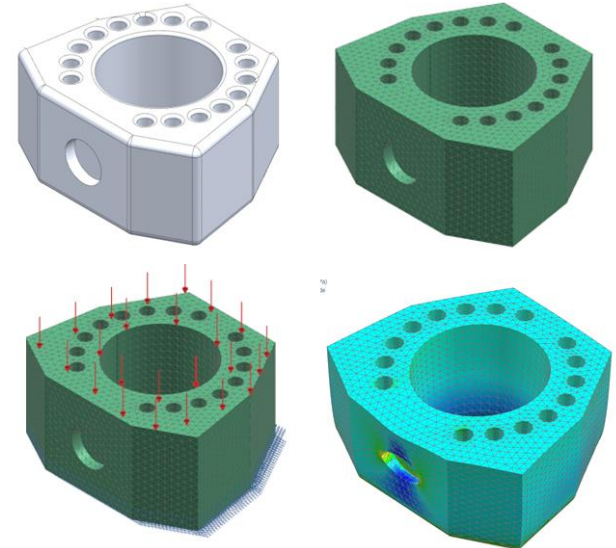

Fig. 3. Numerical simulation algorithm: 1. CAD model creation (left up); 2. FE model creation (right up); 3. Boundary conditions definition (left down); 4. Numerical and graphical results analysis (right down)

\subsection{Numerical simulation 1 methodics}

Intervertebral cage construction solution was original solid platform design. Material parameters were imported from NX NASTRAN material library. Initial input parameters for FEM processing were defined as compressive axial stress (static load) which is produced by weight of the head, muscles and surrounding tissue. Initial FE model is composed from these parameters: element type $\rightarrow$ CTETRA 10 nodes, element size $\rightarrow 0.5 \mathrm{~mm}$, number of elements $\rightarrow$ 43392, restraint $\rightarrow$ displacement in direction 1,2 and $3(x, y, z)$ prevented, free rotation, load $\rightarrow 50 \mathrm{~N}$, number of time steps $\rightarrow 100$, max time increase $\rightarrow 0.001 \mathrm{sec}$.

Next step was to simulate vertebra like mechanical properties. In systematic study effect of age and loading rate on human cervical spine injury threshold, Pintar et al. (1998) found out compressive axial load which causes serious vertebra injury varies from $2 \mathrm{kN}-7 \mathrm{kN}$. Based on this information load parameter was changed to $7 \mathrm{kN}$ to simulate vertebra fracture load.

\subsection{Numerical simulation 2 methodics}

Intervertebral cage construction solution was topologically optimized based on wall thickness analysis data and data from numerical simulation 1. Construction solution was designed for additive manufacturing technology. Aim of the optimization is material reduction, stiffness reduction due to prevent subsidence effect (Teng et al., 2017; Yin et., 2017; Zhong yet al., 2006). The inner space of the implant is formed by 16 cavities which are interconnected with initial technological apertures. The purpose of these apertures is in having access to each cavity, to be sure there is no presence of extra powder after production process. Optimized construction solution is designed to withstand load of cervical vertebra. It means $7 \mathrm{kN}$ was set as load force. Other input data for numerical simulation were identical as for modified simulation in chapter 2.3.

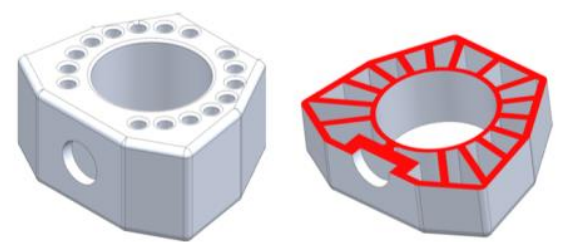

Fig. 4. Topological optimization side view (left), cross section (right) 


\subsection{Experimental testing and numerical simulation based on experimental tested data}

For numerical simulation results confirmation experimental testing was done. There were 20 prototypes produced by fused filament fabrication technology (FFF) printed from E-sun bioplastic PLA material each of which underwent compressive axial testing by electromechanical testing device TIRA TEST2300 that ended with the destruction of the sample.

The purpose of this testing was to gain the true material properties of the alloy in our case of topologically optimized intervertebral cage. Subsequently, these values were used to create numerical computations that simulated the process of the generated tension fields in the implant as a result of a load factor. Through inner sensor of device TIRA TEST2300 were obtained datasets with over a thousand values corresponding to load force $F[\mathrm{kN}]$ induced stress $\sigma[\mathrm{MPa}]$, displacement $\mathrm{P} 1 / \mathrm{P} 2[\mathrm{~mm}]$ and to resulted strains $\varepsilon[-]$ in every loading step for each cage prototype (Fig. 5).

\begin{tabular}{|c|c|c|c|c|c|c|c|}
\hline $1-\mathrm{F}[\mathrm{kN}]$ & $1 \sigma[\mathrm{Mpa}$ & P1-P2[mm] & $1 \varepsilon[-]$ & $2-\mathrm{F}[\mathrm{kN}]$ & $2 \sigma[\mathrm{Mpa}$ & P1-P2[mm] & $2 \varepsilon[-]$ \\
\hline 0.030 & 0.316 & 0.090 & 0.014 & 0.020 & 0.211 & 0.050 & 0.007 \\
\hline 0.030 & 0.316 & 0.100 & 0.015 & 0.000 & 0.000 & 0.060 & 0.009 \\
\hline 0.030 & 0.316 & 0.100 & 0.015 & 0.020 & 0.211 & 0.060 & 0.009 \\
\hline 0.030 & 0.316 & 0.100 & 0.015 & 0.010 & 0.105 & 0.060 & 0.009 \\
\hline 0.030 & 0.316 & 0.110 & 0.017 & 0.010 & 0.105 & 0.070 & 0.010 \\
\hline 0.040 & 0.422 & 0.120 & 0.018 & 0.010 & 0.105 & 0.080 & 0.012 \\
\hline 0.050 & 0.527 & 0.120 & 0.018 & 0.010 & 0.105 & 0.080 & 0.012 \\
\hline 0.050 & 0.527 & 0.120 & 0.018 & 0.020 & 0.211 & 0.080 & 0.012 \\
\hline 0.060 & 0.633 & 0.130 & 0.020 & 0.020 & 0.211 & 0.090 & 0.013 \\
\hline 0.080 & 0.844 & 0.140 & 0.021 & 0.020 & 0.211 & 0.100 & 0.015 \\
\hline 0.090 & 0.949 & 0.140 & 0.021 & 0.040 & 0.422 & 0.100 & 0.015 \\
\hline 0.100 & 1.055 & 0.140 & 0.021 & 0.040 & 0.422 & 0.100 & 0.015 \\
\hline 0.120 & 1.266 & 0.150 & 0.023 & 0.040 & 0.422 & 0.110 & 0.016 \\
\hline 0.140 & 1.477 & 0.150 & 0.023 & 0.050 & 0.527 & 0.120 & 0.018 \\
\hline$\ldots$ & $\ldots$ & $\cdots$ & $\cdots$ & $\cdots$ & $\ldots$ & $\ldots$ & $\ldots$ \\
\hline 5.990 & 63.186 & 3.130 & 0.472 & 5.240 & 55.274 & 3.080 & 0.460 \\
\hline 5.990 & 63.186 & 3.140 & 0.474 & 5.240 & 55.274 & 3.080 & 0.460 \\
\hline 6.010 & 63.397 & 3.140 & 0.474 & 5.260 & 55.485 & 3.090 & 0.461 \\
\hline 6.030 & 63.608 & 3.150 & 0.475 & 5.260 & 55.485 & 3.090 & 0.461 \\
\hline 6.040 & 63.713 & 3.160 & 0.477 & 5.270 & 55.591 & 3.100 & 0.463 \\
\hline 6.050 & 63.819 & 3.160 & 0.477 & 5.280 & 55.696 & 3.100 & 0.463 \\
\hline 6.060 & 63.924 & 3.160 & 0.477 & 5.290 & 55.802 & 3.110 & 0.464 \\
\hline
\end{tabular}

Fig. 5. Measured values corresponding to load force, induced stress, displacement and to resulted strains in every loading step - start and end measurement of prototypes 1,2

After detailed analysis of measured data (Fig. 6) area between $R_{\mathrm{p} 0.2}$ value to $R_{\mathrm{e}}$ value was screened.

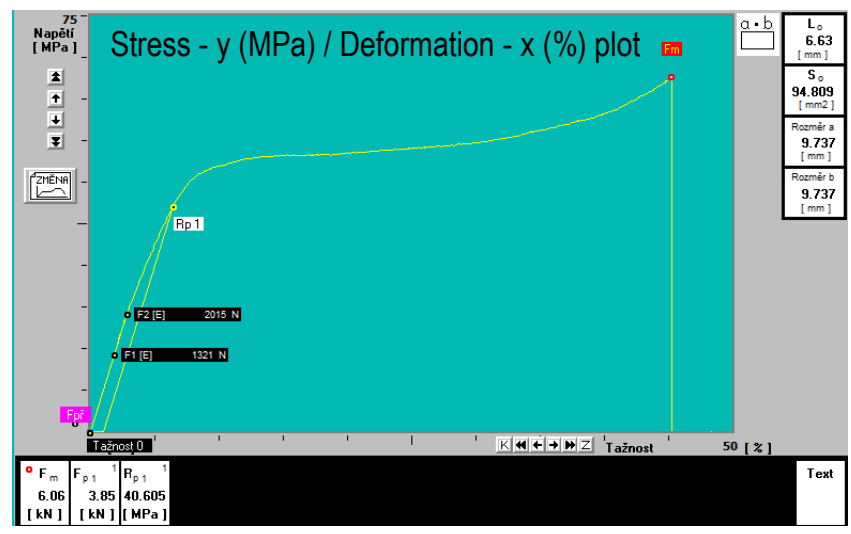

Fig. 6. Pressure testing processing curve - TIRA TEST 2300 (one of 20 intervertebral cage test samples) - screened area between $R_{p 0.2}$ to $R_{e} H$. Maximal values: Stress $75 \mathrm{MPa}$ (step $10 \mathrm{MPa}$ ), Deformation $50 \%$ (step 5\%)

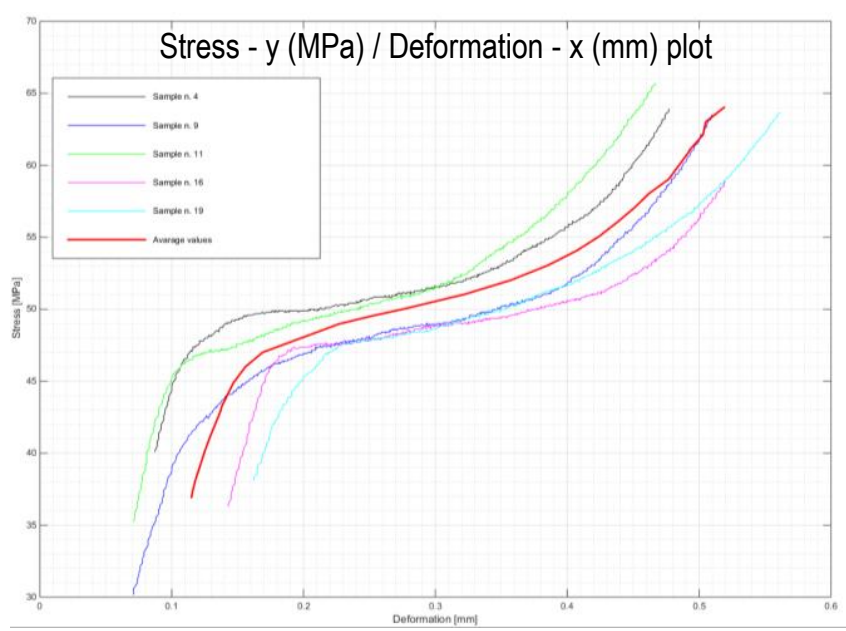

Fig. 7. Curves of experimental testing behaviour - NX NASTRAN ( 5 samples of 20 with average values), Maximum values: Stress $70 \mathrm{MPa}$ (step 10MPa), Deformation $0.6 \mathrm{~mm}$ (step 0.1mm)

The reason why this area was object of study was to examine the behavior of the material made by additive manufacturing technology under biomechanical loads in the cervical spine area, because of anisotropic properties assumption of the material. Input values for simulation based on experimental tested data (Fig.7) of all 20 prototypes were calculated using mathematical and statistical methods.

\section{RESULTS AND DISCUSSION}

This paper investigated numerical and experimental testing of topologically optimized PLA cervical implants and methodics creation of numerical simulation based on FEA. Aim of the optimization was to find out if optimized design prepared for auotologous bone graft injection withstand compressive axial loading as human vertebra in cervical spine (Pintar et al., 1998; Seweryn and Molski, 1996; Sidun and Dabrowski, 2009). Results of initial simulation (Fig. 8) for deformations and displacement were: displacement $\delta=2.058 \times 10^{-3} \mathrm{~mm}$ and maximal equivalent von Mises stress $\sigma_{\text {max }}=0.8 \mathrm{MPa}$.
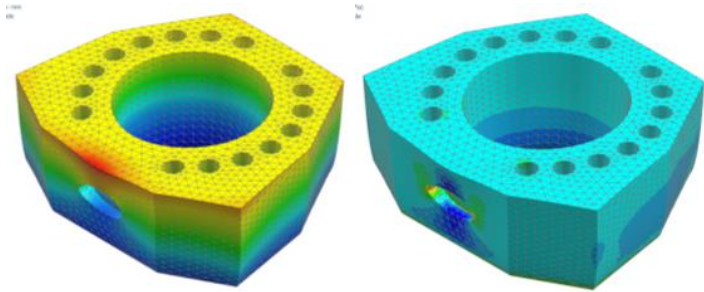

Fig. 8. Results of initial simulation - deformation (left), induced stress field (right)
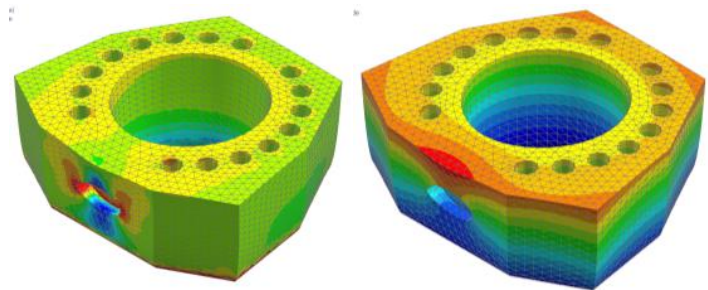

Fig. 9. Results of modified simulation - deformation (left), induced stress field (right) 

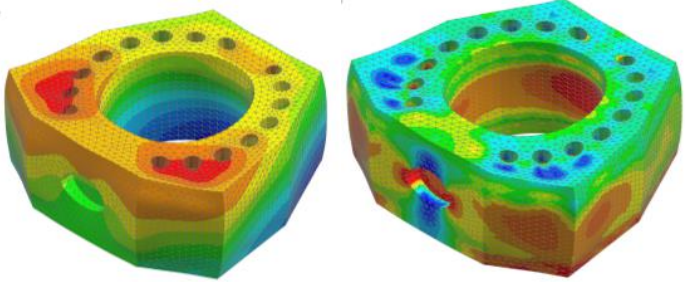

Fig. 10. The resulting deformation (left), induced stress field (right)
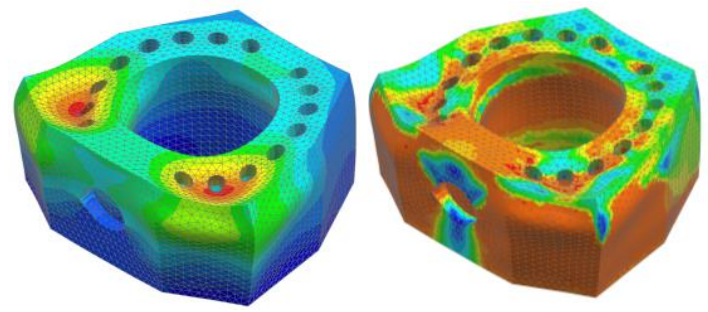

Fig. 11. The resulting deformation (left), induced stress field (right) - real yield strength for simulation based on experimental data

Results of modified simulation (Fig.9) with $7 \mathrm{kN}$ load were: displacement $\delta=0.134 \mathrm{~mm}$ and maximal equivalent von Mises stress $\sigma_{\max }=87 \mathrm{MPa}$.

From results it is seen conventional solid design can withstand load of the segments above the neck and it is suitable for seniors and for passive people regarding compressive axial loading.

Results of optimized cage simulation with $7 \mathrm{kN}$ loading (Fig.10) were: displacement $\delta=0,348 \mathrm{~mm}$ and maximal reduced stress Von Mises $\sigma_{\max }=82.34 \mathrm{MPa}$.

Results of the numerical simulation showed topologically optimized design cannot withstand full compressive axial load of human vertebra on its own. For numerical simulation results confirmation experimental testing was done. Subsequently, values from testing were used to create numerical computations that simulated the process of the generated tension fields in the implant as a result of a load factor.

Results of simulation based on experimental testing (Fig.11) were: displacement $\delta=0.388 \mathrm{~mm}$ and maximal reduced stress Von Mises $\sigma_{\text {max }}=87.29 \mathrm{MPa}$.

After detailed analysis of measured data area between $R_{p 0.2}$ value to $R_{e}$ value was screened. The reason why is this area object of study is to examine the behavior of the material made by additive manufacturing technology under higher loads, because of anisotropic properties assumption of the material. Based on analysis, mathematical, statistical methods and data processing it was concluded that the true average yield strength of the material is $\mathrm{R}_{\mathrm{e}}=63.6 \mathrm{MPa}$, while the yield strength listed in the software material library is $R_{e}=62.7 \mathrm{MPa}$. It can be concluded that with right setting of input material values and properly set numerical values compressive axial simulation can be a tool for implant design verification.

PLA material on its own cannot withstand the same compressive axial loading as autologous human vertebra. Potential of this material is to fulfill the role as a scaffold in combination with autologous bone graft and its following whole biodegradation

\section{REFERENCES}

1. Bocko J., Segl'a Š. (2016), Numerical methods of rigid and pliable bodies, $1^{\text {st }}$ Edition, Technical University of Košice.
2. Chen Y., Wang X., Lu X., Yang L., Yang H., Yuan W., other authors (2013), Comparison of titanium and polyetheretherketone (PEEK) cages in the surgical treatment of multilevel cervical spondylotic myelopathy: a prospective, randomized, control study with over 7-year follow-up, European Spine Journal. 22(7), 1539-1546.

3. Eck K.R., Bridwell K.H., Ungacta F.F. Ungacta, Lapp M.A., Lenke L.G., Riew. (2000), Analysis of titanium mesh cages in adults with minimum two-year follow-up, Spine, 25(18), 2407-2415.

4. Gillet P., Cessotto S., (2008), Mechanics of bones, Montefiore Institute lecture available online: http://www.montefiore.ulg.ac.be/ systems/GBIO/gbio001/chap_2.3.pdf

5. Gzik M., Wolański W., Tejszerska D. (2008), Experimental determination of cervical spine mechanical properties, Acta of Bioengineering and Biomechanics, 10(4), 49-54.

6. Ivančo V., Kubín K., Kostolný K. (1994), Finite Element Method, $1^{\text {st }}$ Edition, Elfa, Košice

7. Kandziora F., Pflugmacher R., Schäfer J., Born C., Duda G., Haas N.P. ( 2001), Biomechanical comparison of cervical spine interbody fusion cages, Spine, 26(17), 1850-1857.

8. Kani K.K., Chew FS. (2018), Anterior cervical discectomy and fusion: review and update for radiologists, Skeletal Radiology, 47(1), $7-17$

9. Mathisen K.M. (2012), Solution methods for nonlinear finite element analysis (NFEA), Norwegian University of Science and Technology Lecture 11: Geilo Winter School - January, available online: https://www.sintef.no/globalassets/project/evitameeting/2012/kmmgeilo-2012-lecture-11a.pdf

10. Mende K., Eicker S., Weber F. (2018), Cage deviation in the subaxial cervical spine in relation to implant position in the sagittal plane, Neurosurgical Review, 41(1), 267-274.

11. NX NASTRAN (2017), Material library.

12. Pintar F.A, Yoganandan N, Voo L. (1998), Effect of age and loading rate on human cervical spine injury threshold, Spine, 23(18), 2407-2415

13. Seweryn A, Molski K. (1996), Elastic stress singularities and corresponding generalized stress intensity factors for angular corners under various boundary conditions, Engineering Fracture Mechanics, 55(4), 529-556,

14. Sidun J., Dabrowski J. (2009), Bone Ingrowth Processes on Porous Metalic Implants, Solid State Phenomena, 147-149, 776-781.

15. Steffen T., Tsantrizos A., Fruth I., Aebi M. (2000), Cages: designs and concepts, European Spine Journal, 9(1), 89-94.

16. Teng L., Chao L., Baohui Y., Jiantao L., Feng Z., Dong W., Haopeng L., Xijing H. (2017), Single-Level Anterior Cervical Corpectomy and Fusion Using a New 3D-Printed Anatomy-Adaptive Titanium Mesh Cage for Treatment of Cervical Spondylotic Myelopathy and Ossification of the Posterior Longitudinal Ligament: A Retrospective Case Series Study, Medical Science Monitor, 23:3105-3114.

17. Wang K. (1996), The use of titanium for medical applications in the USA, Material Science Engineering, 213, 134-137.

18. Yin X., Jiang L., Yang J., other authors (2017), Application of biodegradable 3D-printed cage for cervical diseases via anterior cervical discectomy and fusion (ACDF): an in vitro biomechanical study, Biotechnology Letters, Springer, 39(9), 1433-1439

19. Zhong Z.CH., other authors (2006), Finite element analysis of the lumbar spine with a new cage using a topology optimization method, Medical Engineering \& Physics, 28(1), 90-98.

20. Živčák J., Hudák R. (2001), Biomechanisms, ManaCon, Prešov.

Acknowledgement: This work was supported by research grants: APVV Slovak Research and Development Agency-15-0356, 07/2016 - 06/2019, Analysis of the PEEK polymer and the additive manufacturing possibilities; Design and technology support in the diagnostics of components and engineering units by means of computer tomography (ITMS No. 26220220038); APVV-14-0294,07/2015-6/2018 Production and testing of custom made hard tissues replacements from Hydroxyapatite by $3 D$ printing technology. 